Hispania Sacra, LXII

125, enero-junio 2010, 213-241, ISSN: 0018-215-X

\title{
PERSIA EN LA ACCIÓN CONJUNTA DEL PAPADO Y LA MONARQUÍA HISPÁNICA. APROXIMACIÓN A LA ACTUACIÓN DE LA COMPAÑÍA DE JESÚS (1549-1649)
}

\author{
POR \\ ENRIQUe GARCÍA HERNÁN \\ Instituto de Historia. CSIC
}

\section{RESUMEN}

En este artículo se analizan los orígenes de la misión de la Compañía de Jesús durante los siglos XVI y XVII en Persia, hasta 1649, cuando comenzó propiamente hablando la primera Misión de los Jesuitas en Persia, llevada a cabo por padres franceses, y no por portugueses y españoles como cabía esperar en un principio. Las posturas más extremas de algunos enviados y la división entre las órdenes religiosas serán un problema en el momento de la misión con fatales consecuencias. Utilizamos documentación inédita procedente del Archivo General de Simancas.

PAlabRAS ClaVE: Compañía de Jesús, Monarquía Hispánica, Persia, Edad Moderna, Carmelitas, Agustinos

\section{PERSIA IN THE JOINT ACTION OF THE PAPACY AND THE SPANISH MONARCHY. AN ESTIMATION OF SOCIETY OF JESUS ACTIVITIES}

\begin{abstract}
This article uses unpublished documents preserved at the Archivo General de Simancas to analyze the origins of the Society of Jesus mission to Persia during the sixteenth and seventeenth centuries, until 1649 when, strictly speaking, the first mission to Persia was undertaken by French rather than Portuguese and Spanish priests since it was necessary to defer matters. The most extreme attitudes of some envoys and the divisions among the religious orders represented a problem with fatal consequences for the mission.
\end{abstract}


KEY WORDS: Society of Jesus, Spanish Monarchy, Persia, Early Modern Period, Carmelites, Agustinians

Recibido/Received 2008-02-07

Aceptado/Accepted 2008-09-30

El enfrentamiento entre Persia y el Imperio otomano fue visto desde la Monarquía hispánica y desde el Papado como la mejor ocasión para que la dinastía persa safawi fuera un fiel aliado, pese a la diferencia de religión. En este artículo nos centraremos principalmente en la actuación de la Compañía de Jesús durante un siglo, desde 1549, cuando llega el primer jesuita a Ormuz, hasta 1649, cuando comenzó propiamente hablando la primera Misión de los Jesuitas en Persia, llevada a cabo por padres franceses, y no por portugueses y españoles como cabía esperar en un principio. La Santa Sede encontrará numerosas dificultades para asentar una eficaz actividad apostólica y unas fluidas relaciones diplomáticas con Persia. En primer lugar fueron enviados misioneros agustinos y carmelitas; luego, en 1600 el papa programó, junto con el rey de España, una misión permanente de jesuitas, pero finalmente no tuvo éxito. Las posturas más extremas de algunos enviados y la división entre las órdenes religiosas serán un problema en el momento de la misión. Nos serviremos especialmente de documentación inédita procedente del Archivo General de Simancas. ${ }^{1}$

El Sah Ismail (1500-1524), quien desde 1510 había extendido su dominio a todo Irán, Mesopotamia y Armenia, de modo que sus dominios limitaban con el Imperio otomano, se percató de la necesidad de crear una alianza con las potencias cristianas europeas para oponerse a los otomanos, toda vez desde la presencia militar de los portugueses en Orzmuz (1507). Carlos V también estudió esta posible alianza y fue el primero en tomar la iniciativa, de modo que, en calidad de emperador de Alemania se puso en contacto con Ismail en la década de 1520 para encontrar cauces de colaboración. Como reacción a ese acercamiento, el Sha Tahmasp le envió una carta en 1523 en la que le expresaba su esperanza de que se unieran ambos ejércitos para vencer a los otomanos. Persia se convertía así, en el contexto de la estrategia internacional de los monarcas hispanos y de los pontífices, en un posible aliado, que desde un punto de vista estratégico se encontraba a la espalda del enemigo común otomano.

Más adelante, en 1566, el emperador Maximiliano II, el rey Felipe II y el rey de Portugal decidieron enviar al Sha Tahmasp una embajada para ofrecerle

\footnotetext{
${ }^{1}$ Los aspectos específicos del papel de la Santa Sede han sido presentados en el Congreso Iran and the World in the Safavid Age, organizado por The Iran Heritage Foundation - The Centre for Historical Research on the Middle East, The Centre for Near and Middle Esatern Studies, Londres, 4-7 septiembre 2002, con el título: The Holy See, the Spanic Monarchy and Persia in the Sixteenth Century. Some Aspects of the Jesuit Order's Involvement. Quiero agradecer la ayuda Luis Gil Fernández, Carlos Alonso, Jorge Flores y Ruddi Matthei para la realización de este artículo.

Hispania Sacra, LXII

125, enero-junio 2010, 213-241, ISSN: 0018-215-X
} 
amistad y colaboración, por cuanto Don Sebastián había recibido una invitación del Sha de Persia a través de Antón de Noroña, virrey de India, y el capitán de Ormuz. En esta ciudad cosmopolita portuguesa (1507-1622) confluían persas, turcos, árabes, armenios, abisinios, indios, chinos, portugueses, etc., entrecruzándose musulmanes, judíos, cristianos, paganos. ${ }^{2}$

La Santa Sede tenía conocimiento de lo que allí pasaba gracias a los jesuitas; el holandés Gaspar Berze (1515-1553) residió allí durante varios años, de 1549 a 1551. Fue enviado a Ormuz por Francisco Javier con la obligación de permanecer allí, verdadera encrucijada de Oriente, durante al menos tres años. Observó que en Ormuz había tráfico ilícito de armas con moros y turcos, cosa que prohibía la bula In Coena Domini, sancionando con excomunión la venta de armas, acero y azufre a los «enemigos de la fe». El azufre provenía de la tierra firme de Persia frente a la ciudad de Ormuz. Las disposiciones de la bula podían ser dispensables en circunstancias especiales. Sin embargo, los judíos podían ser intermediarios, verdaderos comerciantes de asuntos militares, pues a ellos, al no ser cristianos, no les afecta la excomunión. En Ormuz había muchos judíos hispanos, en gran parte cristianos nuevos de España y Portugal que, pasando por Venecia, habían llegado al Golfo Pérsico y habían retornado a la fe de sus padres.

El padre Berze veía que en Ormuz tenía poco éxito apostólico, por lo que quería adentrarse en Persia. De hecho, había pensado escribir al Sha Thamasp un detallado informe sobre los errores de su religión, así como rogarle que enviara a Ormuz, dado que él no podía ir a Persia, alguno de sus doctores para mantener con ellos una conversación sobre la fe. Si Francisco Javier se lo autorizaba, estaba dispuesto a ir él mismo a Persia. Berze compartía la opinión generalizada de los príncipes cristianos de que los persas no querían hacer la guerra al gran Turco.

\footnotetext{
2 Para ampliar los caracteres del conflicto Otomano-Safawí resultan muy útiles las obras de A. Allouche, The origins and development of the Ottoman-Safavid conflict (906-962/1500-1555), (Berlín, 1983); J. L. BACQUÉ-Grammont, Les Ottomans, les Safavides et leur voisins, (Estambul, 1987); Richard G. Hovannisian and Georges SABAGH eds., The Persian presence in the Islamic world, (Cambridge: Cambridge University Press, 1998). Sobre los caballeros persianos, véase Enrique GARCíA HERnÁn, «Some Persian Gentlemen at the Spanish Court of Philip III», en Jorge Flores - Ruddi Matthee (eds.), Portugal, the Persian Gulf and Safavid Persia (Leuven, Peeters, 2010 o 2011). Respecto a la presencia hispano-portuguesa, es fundamental el libro de Luis GIL FERNÁNDEZ, El Imperio Luso-Español y la Persia Safávida, Tomo I (1582-1605), Tomo II (1606-1622), (Madrid: FUE, 20062009), Sobre la Iglesia Católica en Irán y las diferentes Órdenes Religiosas Misioneras, véase especialmente para los inicios del siglo XVII respecto la Compañía de Jesús el artículo de Carlos ALONso, «Clemente VIII y la fundación de las misiones católicas en Persia. Un capítulo previo a la penetración de los misioneros agustinos», La Ciudad de Dios 171 (1958) 196-239; Angelo Bugnini, La Chiesa in Iran (Roma, 1981); V. PreIss, De restauratione missionum in Persia saec. XVII Poloniaeque partibus (Disss. PUUrbanian, Roma, 1936).
} 
Al menos Berze consiguió en 1550 una disputa con un filósofo musulmán de Persia, el embajador Zaïde Maduny, quien procedente de Chaul en una embajada en India, había llegado a Ormuz. Berze consiguió la conversión de su esposa y de su hija. Asimismo consiguió que una embajada portuguesa fuera a Persia a renovar la mutua alianza, pese al incidente con Zaïde Maduny, porque el Sha necesitaba la artillería y armas de los portugueses en su lucha contra los turcos. Uno de los datos costumbristas que más asombraba a Berze era que los persas consideraban al Sha como un dios, es más, decía con extrañeza: «el agua con que se lava los pies la toman todos como reliquias para curar con ella todas las enfermedades». ${ }^{3}$ Pese a todos los esfuerzos, no se obtenían éxitos considerables, y el provincial de la India determinó que hubiera cada año un sacerdote distinto por su insalubridad y por el poco fruto apostólico que se lograba. Pese a ello, la Compañía de Jesús dispondrá de cierta información sobre la situación en Ormuz. ${ }^{4}$ Sabemos también que el padre portugués Enrique de Macedo enviaba informes a Berze sobre lo que pasaba en Tabriz..$^{5}$ La documentación que reporta la colección Documenta Indica no nos aporta nuevos datos sobre la actividad de los jesuitas en Persia en este período, posiblemente porque no se consideró una misión prioritaria y la actuación de Berze más bien era una excepción.

Desde el punto de vista político, la alianza persa seguía siendo importante para los príncipes cristianos. Felipe II pidió en 1567 a su embajador en Lisboa que le enviara un informe detallado sobre el mejor modo de llegar a Persia, la categoría personal que debía ostentar un eventual embajador, los emolumentos de los embajadores del rey de Portugal en esa corte, el tratamiento que había de darse al Sah, la lengua en la que se debía escribir y los presentes más apreciados por los persas. El rey deseaba enviar una embajada junto con el emperador. Esta misión llegará a Lisboa demasiado tarde, cuando las naves ya habían zarpado. ${ }^{6}$ Otro

\footnotetext{
${ }^{3}$ Georg Schurhammer, Francisco Javier, su vida y su tiempo, IV, (Pamplona, 1992), vol. IV pp. 484-519.

4 J. Aubin, «Le royaume d'Ormuz au début du XVIe siècle», Mare Luso-Indicum 2 (Ginebra, 1973) 77-179. Niels SteEnsgaord, The Asian Trade Revolution of the Seventeenth Century, (Chicago 1974); Diccionario Histórico de la Compañía de Jesús (Madrid-Roma, 2001), I, p. 427. Véase también N. TRIGAult, Vita Gasparis Barzaei Belgae (Antuerpiae, 1610 y Douai 1615).

${ }^{5}$ Bibloteca de Ajuda, Jesuítas na Ásia, n. ${ }^{\circ}$ 177, fl. 44. Cod. 49-IV-50. Carta [copia] de Henrique DE MACEDO, que estaba en Xiraz, en Persia, al padre maestro Gaspar, Tabriz, 23 agosto 1550.

${ }^{6}$ Archivo General de Simancas. E. 385, 54, 58, 59. Maximiliano II al Sha; instrucción para Jacobo Draperis, «lo que el emperador escribe sobre la embajada de Persia» y «Apuntamientos del emperador sobre la embajada del persiano». El embajador en Lisboa era don Alonso de Tovar, véase su «Relación del viaje de Portugal a Persia, 7 enero 1567», en Archivo General de Simancas. E. 385, 55. El rey de Portugal se comunicaba con el de Persia por vía del virrey de la India y del capitán de Ormuz. Las naves zarpaban de Lisboa para Goa una vez al año -marzo o abril-, y las que iban de Goa a Ormuz dos veces -noviembre-diciembre y a finales de marzo-. La travesía en invierno se hacía costeando la India hasta el estrecho de Ormuz, y la de la primavera tomaba el cabo de Rosalgate. Una y otra duraban un mes, desde Ormuz a la corte persa se tardaba otro mes.
}

Hispania Sacra, LXII

125, enero-junio 2010, 213-241, ISSN: 0018-215-X 
momento fue en 1572 cuando, con ocasión de la victoria de Lepanto, la Santa Sede, Venecia y España con Portugal enviaron emisarios al rey de Abisinia y a los soberanos de Arabia Felix y Arabaia fronteriza con Siria con el fin de ordenar un ataque contra los turcos. ${ }^{7}$

Del mismo modo que los monarcas españoles intentaron crear un sistema de alianzas con los enemigos de la Sublime Puerta para mitigar sus ansias de conquista, los persas buscaron apoyo en los monarcas cristianos para frenar el avance otomano. Aunque nunca dejaron de contemplar la posibilidad de tomar Ormuz, de ahí que no desaprovecharan la ocasión brindada por los holandeses de apoyo militar para este efecto en 1622. A lo largo del siglo XVI, por tanto, la Monarquía luso-hispánica intentó crear una alianza estable con aquellos gobernantes que pudieran servir a este propósito, financiando o enviando emisarios a la península balcánica, el Norte de África y Europa oriental, y, por supuesto, a Persia. ${ }^{8}$ El virrey de Portugal reconocerá en 1601 que Felipe II siempre quiso mantener contacto diplomático con Persia con el exclusivo fin de concertar una alianza contra el turco. ${ }^{9}$

\section{El PONTIFICADO DE PÍO V (1566-1572)}

La Sede Apostólica comenzó a mostrarse favorable a pedir la colaboración de los persas durante el pontificado de Pío V, el cual había emprendido una gran ofensiva contra los turcos por medio de la Liga Santa (1571-1573), confederación hispano-véneto-pontificia, con el firme propósito de recuperar Jerusalén a toda costa. ${ }^{10}$ Después de un lento y complicado iter diplomático-jurídico-mili-

\footnotetext{
${ }^{7}$ Carlos Alonso, «Embajadores de Persia en las cortes de Praga, Roma y Valladolid (16001601)», Anthologica Annua 36 (1989)11-271; Carlos Alonso, La embajada a Persia de D. García de Silva y Figueroa (1612-1624), (Badajoz, 1993). Sobre la imagen de los otomanos en la España del momento resultan muy útiles los trabajos de A. MAs, Les Turcs dans la littérature espagnole du Siècle d'Or (París, 1967), y Miguel Ángel De Bunes IbARRA, La imagen de los musulmanes en la España de los siglos XVI-XVII. Los caracteres de una hostilidad (Madrid, 1989).

8 José María FloRISTÁN Imízcoz, Fuentes para la política oriental de los Austrias: la documentación griega del Archivo de Simancas, 1571-1621 (León, 1986); A. G. Hess, The Forgotten frontier (Chicago, 1978); C. Rodríguez Joulian De SAInT-Cyr, Felipe III y el rey del Cuco (Madrid, 1954). Archivo General de Simancas

${ }_{9}^{9}$ AGS. E. 493. Cristóbal de Moura a Felipe III, Lisboa, 27 octubre 1601. «Y así las veces que el rey, que haya gloria, le escribió, nunca trató de otra cosa que de animarle contra el turco y ofrecerle que por acá sería gallardamente ayudado, para que todos en un mismo tiempo hiciesen daño al enemigo común». Vid. Carlos Alonso, «Embajadores de Persia en las Cortes de Praga, Roma y Valladolid (16001601)», Anthologica Аnпиа 36 (1989).

${ }^{10}$ Carlos Alonso, «Nueva documentación inédita sobre las misiones agustinianas en la India y en Persia (1571-1609)», Archivo Agustiniano 33 (1970) 253-257; P. Z., NovOA, «El M.R.P. Fr. Melchor de
} 
tar tres estados se confederaban para hacer frente a las pretensiones otomanas de Selím II (1566-1574). El mismo día que se capituló la celebérrima Liga Santa, el papa decidió en solitario, sin el consejo de los cardenales, enviar legados apostólicos a España y Alemania. Felipe II será visitado por el sobrino del papa, el cardenal Alejandrino; Maximiliano II recibirá al cardenal Commendome.

El legado Alejandrino debía asimismo visitar Portugal; y, si se daba el caso, también Francia, como luego así fue. Uno de los puntos de las instrucciones -protegidas muy celosamente- vinculaba a Alejandrino con un personaje internacionalmente admirado, especialmente en España, Portugal e Italia. El papa ordenaba a su sobrino que en lo referente a Portugal siguiera el parecer del general de los jesuitas, el padre Francisco de Borja; es más, le decía clara y llanamente que debía hablar con él de todo, gobernándose según su consejo, y que se entrevistara sólo con quienes Borja determinara. ${ }^{11}$ Borja entraba de lleno en el ambicioso plan del pontífice de unir a la Cristiandad, acabar con la herejía, poner freno al avance turco, expandir el cristianismo por todo el mundo. Borja era una pieza clave del sistema de gobierno pontificio; su calidad de general de los jesuitas, su condición privilegiada como otrora duque de Gandía, y sobre todo sus dotes personales, le hacían especialmente útil para servir al pontificado en misiones bien difíciles.

Pese a que en un principio algunos eclesiásticos propusieron que se enviaran legados a los príncipes herejes para que colaboraran en la lucha contra el turco, el papa se opuso enérgicamente: «nullam concordiam vel pacem debere nec posse esse inter nos et hereticos», dijo solemnemente en el consistorio del 23 de junio 1571. En la mente del papa no estaba entonces la idea de pedir ayuda a luteranos y calvinistas, pero sí contaba con la colaboración del Sha de Persia. Apenas conocida la victoria de Lepanto, no dudó en solicitar su apoyo. ${ }^{12}$ Posiblemente fue el sacerdote portugués Matías Bicudo (Matías Furtado Bigudo) -no parece que fuera jesuita, aunque hay dudas al respecto-, quien pudo sugerir a Pío V la idea de pedir la colaboración de Persia, pues durante varios años había residido en Oriente al servicio de los reyes portugueses, conocía el ambien-

los Ángeles, agustino, primer misionero en Persia», en Archivo Agustiniano 45 (1951) 263-275; Enrique GarCía Hernán, «Pío V y el mesianismo profético», Hispania Sacra 45 (1993) 83-102.

${ }^{11}$ Archivio Segreto Vaticano. Miscell. Arm. II, 82, 392. «Conferirete il tutto co'il sudetto P. Generale, governandovi secondo il suo consiglio, parlando con chi a sua paternità reverenda parerà a proposito et expediente». Véase: Enrique GarCía Hernán, La acción diplomática de Francisco de Borja al servicio del Pontificado (Valencia, 2000).

12 Archivio Segreto Vaticano. Senado, dispaci, Roma, 7, 113, Soriano-Soranzo al dux, Roma, 3 junio 1571. Sobre la elección de Alejandrino, véase ASV. Act. Miscell. 36. En el consistorio del 23 de mayo el papa decidió enviar legados a los príncipes cristianos, el 18 de junio fue elegido oficialmente Alejandrino. Sobre las bulas de su legación véase: ASV. Reg. Vat. 2014, 9 (a Felipe II) y 15 (a Sebastián), con fecha del 18 de junio; otra copia en BAV. Barb. Lat. 2412. AGS. E. 390, 83. Pío V al rey de Persia, 12 noviembre 1571. 
te y había estado recientemente en Madrid y en Roma. No obstante, sobre este personaje hay numerosos interrogantes, pues parece que pasó por diferentes órdenes religiosas y resulta difícil precisar su auténtico currículo vital, hombre escurridizo en el pasado y en el presente, porque los documentos dicen de él que primero fue jesuita y luego franciscano, y luego sacerdote secular. ${ }^{13}$

También hay dudas sobre los auténticos deseos de Pío V, pues cuando el embajador español en Roma le habló de la colaboración persa, le respondió que no quería escribir a Persia por no ser costumbre que los pontífices tuvieran contacto con los infieles. Felipe II pensó que había una gran contradicción, y estimó que al papa se le había olvidado que la negociación ya estaba hecha, de ahí la reacción del rey: «no se le debió acordar»-escribió el rey a su embajador-, toda vez que ya tenía en su poder copia original de los documentos pontificios remitidos al Sha. ${ }^{14}$

En esos documentos Pío V daba cuenta de la victoria de Lepanto al Sha y le exhortaba a aprovechar la favorable circunstancia militar, y le animaba a levantar un ejército para invadir el territorio enemigo, con el fin de resarcirse de las pérdidas que su nación había sufrido con los territorios robados a sus antepasados por Solimán en las regiones de Mesopotamia y Siria. Ignoraba la cancillería pontificia la situación real en Persia, porque las pérdidas a que se alude en el breve se habían producido durante el reinado de Thamps I en 1534 y no de sus predecesores. ${ }^{15}$

Uno de los objetivos de Francisco de Borja en Portugal había sido conseguir que el rey Sebastián secundara los planes estratégicos de Pío V. Desde Lisboa informó directamente a su amigo Marco Antonio Colonna, al mando de la flota pontificia, que se había conseguido la entrada del rey portugués en la liga santa, de modo que ofrecía su ayuda militar. Además, no solamente los portugueses atacarían al turco por el Mar Rojo, sino también por Persia y Etiopía. ${ }^{16}$ Marco Antonio Colonna quedó agradecido por la colaboración portuguesa en una futura campaña militar en Persia, pero pidió a Felipe II -secundando los planes pontificios- que se hiciera todo lo posible para recuperar Constantinopla, que

13 Sobre los Bicudo, véase Marqués DE AzEBedo, Apontamientos históricos... de la provincia de San Paulo, 2 vol., (Rio de Janeiro, 1879). Un célebre miembro de la familia fue Antonio Bicudo, hidalgo muerto en 1650. Véase Esteves Pereira - G. Rodrigues, Portugal. Diccionario histórico, 7 vol., (Lisboa 1904-1915).

${ }^{14}$ AGS. E. 918, 150, Juan de Zúñiga a Felipe II, Roma, 14 marzo 1572.

15 Sobre la batalla naval de Lepanto, véase. David y Enrique GARCíA HERnÁn, Lepanto, el día después (Madrid: Actas, 1999).

${ }^{16}$ Borgia V, p. 647, Borja a Marco Antonio Colonna, Lisboa, 10 diciembre 1571. «Quanto a la liga, che questo principe ci entra molto volontieri, et non solamente per il Mar Rosso et Persico, et per la Ethiopia, vole far guerra al turco, ma anche per questa parte vol dar aiuto alla armata christiana». 
era el objetivo fundamental. ${ }^{17}$ Se debe tener presente que en diciembre de 1571 el rey avisaba a su embajador en Roma que pusiera en marcha el aparato diplomático para conseguir la colaboración de Persia. Así desde Madrid, Lisboa, Roma, Venecia y desde Mesina, donde estaba la flota aliada, se pusieron todos a trabajar para obtener la colaboración del Sha. ${ }^{18}$

Apenas salía de Madrid, el legado Alejandrino dejó encomendado al nuncio en la corte española, Castagna, algunos asuntos referentes a Persia, cinco breves y una carta para el rey don Sebastián de Portugal. Fueron enviados al colector pontificio en Lisboa, monseñor Aspra. Se trataba de secundar la iniciativa de los aliados, conseguir que Persia, Etiopía y Arabia declararan la guerra al turco. Para su consecución se contaba con la ayuda prometida del rey Sebastián, habida cuenta de los muchos contactos que tenía en esos lugares a causa de los viajes portugueses. Aspra debía traducir los breves a las leguas de los destinatarios. ${ }^{19}$ El rey Sebastián aceptó la propuesta y envió un embajador especial a Persia con las cartas del papa, del dux de Venecia y del rey católico. ${ }^{20}$ Traducir los breves y documentos al persa no fue fácil. Indudablemente había portugueses que conocían el persa, pero no solían estar en Lisboa, por eso se decidió que fueran traducidos cuando llegaran a Ormuz, acaso por algún armenio. ${ }^{21}$ Con el

${ }_{17}$ Archivo General de Simancas. E. 918, 271. Marco Antonio Colonna a Felipe II, Roma, 20 enero 1572 .

${ }_{18}$ Archivo General de Simancas. E. 917, 121. Felipe II a Zúñiga, 22 diciembre 1571. «... en lo que toca al Sofi, no hay duda sino que importaría mucho que por todas estas partes se apretase al turco para mayor daño y destrucción suya, y para procurar persona a propósito para esto se hará diligencia por vía de Portugal; y para ello he mandado que se escriba a mi embajador y también para que por parte del rey de Portugal se haga esta diligencia y se advierta al legado para que él ayude por su parte, si ya no fuere partido».

${ }_{19}$ Archivo Segreto Vaticano. SS. Spagna 5, 50. Castagna a Flaminio Donato d'Aspra, Madrid, 12 enero 1572. Copia de los breves en Archivo General de Simancas. E. 390, 82-83-83; 157-158-159, y en ASV. Arm. XLIV, 19, 441. Cartas de Felipe II para los reyes de Persia, Etiopía y Arabia en Archivo General de Simancas. E. 390, 148-150, con fecha del 15 de marzo 1572. Rudimenta linguae Persicae authore Ludovico de Dieu; accedunt duo priora capita Geneseos ex persica translatione Iac. Tawusi (Lugduni Batavorum, ex Officina Elseviriana, 1639), [8], 95 p. 4, Madrid, Palacio Real, Pas. Arm. 1/99 (1).

${ }^{20}$ Archivo General de Simancas. E. 390, 80. Sebastián al rey de Persia, Lisboa, 26 febrero 1572; E. 390, 81. Copia de la instrucción para Miguel de Breu; E. 3990, 161. Felipe II a Juan de Borja, 28 febrero 1572. Véase: Carlos Alonso, A los orígenes de las relaciones entre la Santa Sede y Persia (157172), en M. Fois, S.I., V. Monachino S.I., F. LiTva, S.I., (eds.), Dalla Chiesa antica alla Chiesa moderna. Miscellanea per il Cinquentesimo della Facoltà di Storia Ecclesiastica della Pontificia Università Gregoriana, (Roma, 1983), pp. 215-229. Ver también Luis Gil, «Embajadas de Felipe II a Persia: inútil búsqueda de un aliado contra los turcos», Historia 16178 (1991) 39-46.

${ }^{21}$ Fr. Juan Tadeo de San Eliseo O.C.D. conocía el persa perfectamente. Lodewijk DE DIEU (15901642) publicó en Leiden en 1639 los Rudimenta Linguae Persicae. En 1649 se publicó en Londres los Elementa Linguae Persicae, por John Greaves (1602-1652). Téngase también en cuenta el Alphabetum persium, cum oratione dominicali et salutatione angelica (Romae, typis Sac. Congreg. de Propag. Fide, 1784). En España uno de los pocos que conocían el idioma persa era el vasco Francisco de Gurmendi, que fue nombrado en 1612 traductor oficial del árabe, turco y persa.

Hispania Sacra, LXII

125, enero-junio 2010, 213-241, ISSN: 0018-215-X 
tiempo algunos jesuitas se harán expertos en lengua persa, como el padre Javier, traductor de los Evangelios. Parece, por otro lado, que a finales de siglo algunos jesuitas de India aprendían el idioma, como los padres Antonio Monsarrate y Francisco Enríquez.22

El hombre elegido para llevar los documentos a Persia fue don Miguel de Abreu, un hidalgo portugués que había vivido muchos años en la India. Se embarcaría en las naves que iban a zarpar de Lisboa en el mes de marzo. En las instrucciones para Abreu el rey de Portugal le ordena que debía convencer al Sha para que atacara al turco inmediatamente, porque estaba en juego el bien de todos, por cuanto los aliados cristianos después de la victoria conseguida en Lepanto proseguirían la lucha en nuevos frentes. El emperador y Polonia atacarían desde Hungría, el rey de Portugal desde la India. Ahora había que abrir un frente nuevo en el estrecho del Mar Rojo y desde el reino de Ormuz para hacer el mayor daño posible, y, como decía la instrucción, «que le faça toda la guerra que poder sea». Por parte de la India portuguesa no había duda de que así se haría. Se trataba de conseguir en todos los frentes posibles «sua total destruição». Los príncipes cristianos estaban seguros de que tendrían un aliado en el Sah con el que habría amistad y comercio. ${ }^{23}$ Abreu se dirigiría en primer lugar a Goa, la capital de India, desde donde el virrey le daría todas las facilidades para proseguir su viaje a Ormuz y de allí a Persia.

Es verdad que rey Sebastián estaba dispuesto a participar en la liga contra el turco, y a entrar en la guerra por Asia y por el Mar Rojo, enviando una armada apoyada por abisinios, árabes y egipcios. Había ordenado hacer una gran armada, de 4.000 hombres, para que acudieran en ayuda de la Santa Liga en aquellas partes. Pero antes de adentrarse en esa aventura militar, el rey quería que se castigara a los calvinistas que hacían estragos en sus reinos. Sabía que cerca de setenta naves se aprestaban para atacar a los portugueses en Brasil. ${ }^{24}$ Esto provocó división de pareceres entre los aliados. Una vez solucionado el hostigamiento de calvinistas, hubo dudas fundadas sobre si era estratégicamente correcto enviar 4.000 hombres a Asia, pues parecía mejor engrosar las fuerzas de la Liga Santa y atacar con todas las fuerzas disponibles el corazón mismo del imperio otomano. El embajador véneto, Tiépolo, pensó que se necesitaba ayuda en el Mediterráneo, no en zonas tan alejadas, por lo que pidió a las autoridades

${ }^{22}$ Doc. Ind. XVI, 458. Alberto Laerzio al general Aquaviva, Goa, 28 noviembre 1593, El rey Mogol fue a ver los jesuitas «con molta familiarità et li prego con molta instancia procurassero con ogni diligentia di imparare la lengua, acciò lui potesse entender le cose de la nostra santa fede, et praecipue alcuna cosa del misterio della Santissima Trinita».

${ }^{23}$ Archivo General de Simancas. E. 390, 80. Sebastián de Portugal al rey de Persia, Lisboa 27 febrero 1572. AGS. E. 390, 81. Instrucciones para Miguel de Abreu.

${ }^{24}$ Archivo Stato Venezia. Archivio Proprio Spagna 6, 152, Copia tradotta dalla risposta all'Ambasciatore. 
portuguesas que dijeran exactamente el número de soldados que enviarían «non nelle parte delle Indie, ma delle parte d'Europa». ${ }^{25}$ Don Sebastián decidió que enviaría a Asia 6.000 hombres, porque esto era lo mejor para la Cristiandad, teniendo en cuenta que era lo más fácil, ya que los gastos del rey serían muchos y de poco provecho para la liga por el poco ejército que podía enviar al Mediterráneo. Don Juan de Austria, capitán general de las fuerzas aliadas de la Liga Santa, también era partidario de que el rey Sebastián enviara su armada a Asia, porque los 2.000 soldados que como mucho podrían dar los portugueses para el frente mediterráneo no serían nada comparado con los 6.000 que irían a Asia. Después, los árabes y persas se sublevarían poco a poco al ver tropas portuguesas cerca. ${ }^{26}$

Los documentos pontificios llegaron a manos del embajador español en Lisboa, don Juan de Borja -hijo de Francisco de Borja-, doce horas después de que las naves destinadas a la India abandonaran el puerto lisboeta, que lo habían hecho a primeras horas de la mañana del 18 de marzo de 1572. Todas las gestiones diplomáticas parecían esfumarse. No obstante, se hicieron diferentes trámites para que dichos documentos llegaran a sus destinatarios a través de otros embajadores, pero no hay constancia de cómo se realizó esta operación, si bien disponemos de datos precisos que demuestran que la misión se llegó a realizar con éxito.

Por su parte, Matías Bicudo intentó desde todos los frentes posibles que las fuerzas cristianas se aliaran con los persas para atacar a los otomanos. Sabemos que en 1571 ya había propuesto al virrey de Sicilia entablar negociaciones con «un gran señor de El Cairo». ${ }^{27}$ La propuesta tuvo éxito, pues Don Juan de Austria comunicó al rey que había enviado a Egipto dos espías que le había recomendado Bicudo. ${ }^{28}$ Por aquellas fechas la Compañía de Jesús ya había tenido varias misiones apostólicas importantes en aquellas partes. Los primeros jesuitas en Egipto, Miguel de Nóbrega (1552-1553) y Fulgencio Freire (1560-1563),

${ }^{25}$ Archivio Stato Venezia. Archivio Proprio Spagna 6, 147, Tiépolo a Mocenigo, Almeirin, 19 enero 1572 .

26 Archivio Stato Venezia. Annali, 1571, (antigua signatura Cod. di Brera, 339) 302, 303. Don Sebastián al dux. 24 enero 1572 (colaboración con la liga). Otra de 31 de enero (envío de embajador al rey de Persia). ASVen. Archivio Proprio Spagna, 6, 153, Tiépolo a Mocenigo, 13 febrero 1572.

27 Archivo General de Simancas. E. 1135, 66 y 67.

${ }^{28}$ Archivo General de Simancas. E. 1138. Juan de Austria a Felipe II, Mesina, 2 febrero 1572. «A Alexandría de Egipto he enviado yo dos hombres que Mathías Bicudo, aquel portugués que el año pasado andaba en esa corte, me ha dado a entender lo que por allí se podría hacer, daré aviso a V. M. de la relación que de ellos tuviere. A Rodas, a Corón y a África y a Trípoli y a Constantinopla he enviado estos días hombres a entender el estado en que se hallan allí las cosas, y con algunas pláticas, y tratado. Hasta ver si tienen fundamento de sustancia no quiero cansar a V. M. con escribir las particularidades de ellas». 
vivieron como esclavos. Entre 1561 y 1564 permanecieron en Egipto los padres Cristóbal Rodríguez y Giovanni Battista Eliano como legados apostólicos ante el patriarca copto Gabriel VII con el fin de llegar a la unión entre la Iglesia copta y la romana. Bicudo estaba al tanto de estos movimientos y veía posible una alianza copta en la lucha contra los turcos. No tenemos más noticias de los espías que envío don Juan de Austria, pero sí consta que una década más tarde el nuevo patriarca Juan XIV se mostró más partidario de la unión, así que Gregorio XIII envió una nueva misión, entre 1582 y 1584, con algunos jesuitas, los padres Francesco Sasso y Giovanni Battista Eliano. Pese a que se celebró el Concilio de Menfis, todo terminó con un estrepitoso fracaso, con el encarcelamiento de los jesuitas el 21 de septiembre de 1584. Al año siguiente fueron rescatados.

Mientras se mantuvo unida la Liga Santa (1571-1573), los políticos españoles se fueron dando cuenta de la necesidad de que también el Sha y otros príncipes entraran en la confederación. Posiblemente también se enviaron cartas similares al duque de Moscovia, al rey de Polonia, y las provincias de cristianos que había en el Mar Negro. Don Juan de Austria, al menos, escribió en este sentido a los cristianos de Rodas, y buscó la alianza de los griegos del Brazo de Maina. ${ }^{29}$

También sabemos que en Roma el cardenal Amulio, que era el embajador véneto ante al Santa Sede, tenía inteligencias con Matías Bicudo, el cual había comenzaba a suscitar sospechas entre los diplomáticos españoles sobre sus verdaderas intenciones. Había ideado un sistema casi perfecto para apoderarse de Alejandría. La idea fue asimismo presentada al cardenal español Gaspar de Quiroga, quien a su vez la presentó a Felipe II. El monarca, apenas conoció el plan lo aprobó abiertamente. El rey había visto personalmente al sacerdote portugués Bicudo y creía que daba buena razón de todo, y aunque no podía tomar una resolución definitiva sobre su propuesta, Bicudo tenía razón respecto a los designios de la armada enemiga, por tanto se debía contar con él para misiones en oriente. Felipe II era partidario del proyecto, pero no quiso dejar huella de su decisión, pues la respuesta que dio a Quiroga no fue registrada en la cancillería, ni pasó por el secretario Antonio Pérez, sino que la contestación fue de su puño y letra en la misma carta de Quiroga, incluso el monarca escribió en el dorso: «Al obispo de Cuenca, en su mano», cosa inusual en él. En efecto, el Rey Prudente aceptaba sin condiciones el plan, pero también deseaba conocer la opinión de sus consejeros más cercanos a los acontecimientos, lo cual im-

${ }^{29}$ Colección de Documentos Inéditos para la Historia de España, 113 vols, (Madrid 1842-1895), III, 351. Don Juan de Austria a los cristianos de la isla de Rodas, Mesina 15 de enero 1572. Véase Enrique GARCÍA HERNÁN, «The price of spying at the Battle of Lepanto», Eurosian Studies II/2 (2003) 227-250; y del mismo autor «Intento de unión de la Iglesia Latina con la Iglesia Ortodoxa en 1571», Eritheia 24 (2003) 159-178. 
plicaba movilizar dictámenes y recursos económicos procedentes de Roma, Nápoles y Sicilia. Como vemos, Felipe II no actuaba solo, pues «con la diligencia y inteligencia de estos tres [cardenal Quiroga, cardenal Granvela y el marqués de Pescara] desde allá podrá ser que se hiciese algo de dinero». Pero el plan se paralizó precisamente porque los tres no lo vieron viable, y Matías Bicudo fue perdiendo reputación. 30

\section{EL PONTIFICADO DE GREGORIO XIII (1572-1585)}

Hemos visto cómo don Sebastián de Portugal envió una embajada al Sha Thamasp de Persia a cargo de Miguel de Abreu de Lima, el cual llevaba también la representación del papa Pío V, del rey Felipe II y del dux de Venecia.31 De la misión de Abreu hay pocas noticias. Robert Gulbenkian dudó de que llegara a la capital del Sofi, sin embargo, el agustino Melchor de los Ángeles nos dice que sí se realizó esa misión, pero con poco éxito. ${ }^{32}$

Pasados unos años del intento de la Liga Santa de 1571, don Juan de Austria, ante las insistencia de Matías Bicudo, decidió enviar por su cuenta una embajada a Persia sirviéndose del griego Marcos Trastópulo, de Luis de Portillo y del obispo de Stonj, los cuales residían en Ragusa junto con Matías Bicudo. ${ }^{33} \mathrm{Se}$

30 Archivo General de Simancas. E. 153, 155. Obispo de Cuenca a Felipe II con la respuesta dentro: «entendido lo de la liga y lo que hace el Turco, que no podrá dejar de saberse pronto, podremos ir con quienes será bien tratar de esto, y creo que entonces lo será escribir al cardenal Granvela, que tiene mucha noticia de estas cosas, que las tratase con el cardenal Amulio, y que entre ambos desde allí [Roma] se comunicasen con el marqués de Pescara [virrey de Sicilia] a quien también se podrá escribirle sobre ello». AGS. E. 1134, 164. Juan de Austria a Felipe II, Mesina, 25 noviembre 1571. «V. M. se debe acordar de un portugués que andaba en esa corte cuando yo partí de ella que se llama Matías Bicudo, el cual fue encaminado por el cardenal Amulio al obispo de Cuenca y trataba de ser parte para rendir en los confines del Cayro y Alexandria un gran señor vasallo del Turco. Este se halla al presente en Roma y escrito a don Juan de Zúñiga que me lo envíe con intención de que haga el viaje que ha ofrecido, particularmente así que el negocio tiene algún fundamento de agora tiempo de intentarlo. Llegado aquí pienso despacharle y avisar a V. M. de lo que con él se tratare...». Véase sobre el contexto de la defensa del Mediterráneo, Enrique García Hernán, La armada española en la Monarquía de Felipe II y la defensa de Mediterráneo (Madrid: Tempo, 1995).

${ }^{31}$ Archivo General de Simancas. E. 390, 80. Copia de la carta que el serenísimo rey de Portugal escribió a Xathamas, rey de Persia, en 26 febrero 1572. Archivo General de Simancas. E. 390, 81. Copia de la instrucción que el serenísimo rey de Portugal dio al embajador que envió al rey de Persia, Miguel Dabreu.

${ }^{32}$ L'Ambassade en Perse de Luis Pereira de Lacerda et des Pères Portugais de l'Orde de Saint Agustin Melchor dos Anjos et Guilherme de Santo Agostinho, 1604-1605 (Lisboa, 1972), p. 28. Véase Archivo General de Simancas. E. 495. «Lo que dicen los dos padres agustinos que han venido de Persia acerca del estado en que está aquella, Melchor de los Ángeles y Juan de San José, 6 enero 1614.

${ }^{33}$ Se trata de Bonifacio de Esteba O. Min. Obs., natural de Ragusa, que fue obispo de Stonj, sede sufragánea de Ragusa desde el 17 de noviembre de 1561 hasta 1582, año en que murió. Eubel, Conradus, Hierarchia Catholica (Monasterii, 1923), III, 304.

Hispania Sacra, LXII

125, enero-junio 2010, 213-241, ISSN: 0018-215-X 
puso entonces en marcha el aparato diplomático, la propuesta fue enviada a los embajadores en Roma y Lisboa. El embajador en Roma esperaba -era julio de 1573 - que llegara pronto Matías Bicudo con el fin de proponer al nuevo papa, Gregorio XIII, que fueran a Persia y Moscovia Luis de Portillo y el obispo de Stonj. Cuando todo estaba preparado se produjo a última hora un importante cambio de planes sin comunicárselo al papa, y se destinó solo al griego Marcos Trastópulo. Todavía no sabemos bien la razón, aunque se entrevé que los otros no eran tan fiables para don Juan de Austria. Bicudo llegó a Ragusa en el verano de 1575, pudo colocar en Constantinopla un agente que le informó de las actividades del sultán, y apenas hubo llegado comenzó a preparar la misión de un agente suyo en Persia. ${ }^{34}$

Con respecto a la misión de Abreu de 1572, hay noticias ciertas de que en noviembre de 1576 el colector pontificio de Portugal comunicaba al cardenal de Como que el mes anterior había regresado de la India un tal Horacio de Milán, el cual había sido prisionero de los turcos durante el asedio de 1570 a Famagusta, pero que había logrado huir a Persia, donde encontró en Casbín un joyero llamado Mario Greco, el cual iba en compañía de un embajador portugués que había sido mandado a Persia por el papa y Felipe II con credenciales. Luego Horacio de Milán pasó por Ormuz y Goa camino de Europa. Parece que este Mario Greco se entrevistó con el Sha y luego volvió a Roma. Posiblemente el embajador que se nombra en este documento sea nuestro Abreu y que Mario Greco fuera un enviado de Gregorio XIII y de Felipe II con el fin de conocer el resultado de las negociaciones iniciadas durante el pontificado de Pío V. De hecho, consta que Gregorio XIII en febrero de 1584 envió un emisario con cartas suyas para el Sha, como más adelante veremos.

Contamos con una relación de diciembre de 1575 de lo sucedido con una embajada hispano-luso-pontificia a Persia que confirma nuestras sospechas. Se trata de la misión de Francisco de Barros, enviado en 1572, posiblemente el que sustituyó a Abreu, pero que no tuvo ningún éxito, pues el Sha no quiso concertar una alianza. En la cancillería española todo este asunto provocó un informe que un secretario bien informado incluyó en nota marginal sobre los temas relacionados con el Oriente, y pensamos que vale la pena transcribir porque nos proporciona datos concretos sobre la misión de Abreu: «Este embajador [Abreu] fue enviado por parte de Su Santidad, el rey nuestro señor y el rey de Portugal, al cual el Sr. Don Juan envió un hombre y cédula de 12.000 ducados para si hubiera menester dineros, y se partió de Portugal y se detuvo como dos años en llegar, y llegó el 26 de febrero de 1575, y el embajador llegó cuando éste partió de Ormuz. Que le tenían al embajador del rey en Casbin muy apreta-

\footnotetext{
${ }^{34}$ Contamos con seis cartas de Bicudo fechadas en Ragusa, 29-VIII; 13-IX; 1-X; 26-X; 9-XI; y 1XII. Archivo General de Simancas. E. 1517., 1, 9, 23, 24, 27 y 30, respectivamente.
} 
do y maltratado en una casilla que no se puede habitar y que el sobrino del rey, que es el que gobierna por ser el rey viejo, que se maravillaba cómo un rey tan grande como el de Portugal no había enviado al rey Xatamas [Thamasp] que es tan poderoso que llega a los cielos presente de dos cuentos de oro. Y parece ser que llegó presente hasta de 16.000 ducados en dinero y joyas y piezas de ellas, se las devolvieron con una cama que valdría 500 o 600 ducados, la cual tiene consigo el embajador.... le mataron un criado armenio que era su comprador... y estaba para matar al embajador y todos sus hombres que serían 20, y de miedo uno de ellos se tornó moro... y que la causa dicen porque querían al embajador era porque había entrado en la mezquita de Ormuz y quemado los libros que allí había, y que el embajador respondió que porque ellos habían quebrado la cruz de la iglesia que los portugueses querían hacer, y que ellos respondieron que por causa de aquel palo habían de hacer aquel daño en la mezquita, y que el embajador había dicho que por aquel palo habían sido redimidos los cristianos y que le habían dejado y se había tratado otra cosa y le tenían detenido allí. Que este rey es el rey de Persia. Que el rey de Persia le recibió muy bien y que después que le vio y entendió su embajada, que era para que rompiese guerra, se agravió y comenzó a hacer maltratamiento sin responder ni decirle nada a su embajada, y no se vio más con el rey ni le habló, sino a un sobrino».35

En 1576 también el rey envió a Persia un emisario armenio, un tal Juan Bautista, el cual llegará a tener también un encuentro con el Sha. Mientras, en Persia, Thamasp fue asesinado en 1576 y efímeramente sucedido por varios soberanos. Reinó luego Mohamed Khudabanda (1577-1587), hombre que ha sido considerado débil. El sultán turco Murad III decidió un ataque directo en 1578, provocando una serie de derrotas. Un emisario del Sha fue a Portugal en 1579 para solicitar ayuda. Pero la situación real era que hasta 1580 Felipe II pudo disfrutar de cierta paz respecto al problema turco, gracias principalmente a las treguas. ${ }^{36}$ Treguas en gran medida obligadas, ya que el turco debía hacer frente a los persas y Felipe II a las diferentes presiones inglesas y francesas. Las empresas militares turcas se trasladaron al ámbito terrestre. ${ }^{37}$ Con todo, no faltaron avisos diciendo que los turcos para el verano enviarían a España 300 galeras, para poner en alerta con estas amenazas al rey católico, lo cual suponía realizar

${ }^{35}$ Archivo General de Simancas. E. 1517. 12-XII-1575.

${ }^{36}$ La primera comienza en 1577 y se irán renovando hasta 1593. El milanés Juan de Marigliano será el encargado de negocios de la monarquía hispánica ante Constantinopla. Enrique II hizo todo lo posible para estorbar las treguas, curiosamente con la colaboración de la Santa Sede. Los turcos querían engañar a los franceses asegurándoles que no existía tal tregua. Enrique III al Abbé de Lile. Poistiers 7 septiembre 1577. Enrique GARCíA HERnÁn, La armada española en la Monarquía de Felipe II y la defensa de Mediterráneo (Madrid: Tempo, 1995), pp. 55-60.

${ }^{37}$ Biblioteca Apostolica Vaticana. Urb. Lat. 831, 487. «Le provincie presse dal gran Turco, cominciando dall'anno 1577».

Hispania Sacra, LXII

125, enero-junio 2010, 213-241, ISSN: 0018-215-X 
más gastos. Eran avisos confusos, pues se sabía que en realidad los otomanos no querían iniciar un ataque frente a frente, sino en todo caso seguir con sus escaramuzas, y que Felipe II gastara su dinero en defenderse de posibles ataques. De todas formas, decía un confidente bien informado que era preciso estar con cuidado, porque no se podía confiar en las promesas de gente tan desvariada como los otomanos, y mucho menos de su buena voluntad..$^{38}$

Hubo nuevos intentos de colaboración hispano-persa, que debemos mencionar siquiera brevemente. En 1582 Frei Simao de Moiras, prior del convento agustino de Ormuz, llevó al Sha cartas de Felipe II para proponer de nuevo una alianza militar para luchar contra los turcos. ${ }^{39}$ El Sha se mostró, esta vez, propicio a un intercambio de embajadores. Contemplamos cómo a finales del siglo los franceses empiezan a tomar cada vez mayor interés por el comercio con Persia. El residente francés en Madrid, señor de Longlée, dio cuenta a París, en 1583, del anuncio de la llegada de una embajada persa a Lisboa. Parecía abrirse un camino diplomática que podía dar frutos. Pocos años después, en 1586, llegaron a España los ecos de las batallas entre turcos y persas. El poeta castellano Andrés Flores puso en verso el sentimiento que había en España a favor de los persas, amigos de los cristianos. Era una fabulosa propaganda que sirvió para ver con interés renovado todo lo referente a Persia. Vencidos los otomanos, los persas repartieron la presa, decía así:

Tanta de la artillería

tanto oro y plata labrada

tanta joya y pedrería

todo lo cual repartía

con gente esforzada.

Especial a los cristianos

repartió gran cantidad

que los quieren los persianos

como si fueren hermanos

y los muestra su amistad».

Estos versos se imprimieron en Valencia y Burgos en 1586, y contribuyeron a mitificar todo lo referente a Persia. Tan sólo cuatro años más tarde el historiador Antonio Herrera de Tordesillas eligió un tema de actualidad para ganarse la confianza del rey. Tradujo del italiano la obra de médico Juan Tomás Minadoi (1540-1615) titulada Historia de la guerra entre turcos y persianos, que había aparecido por primera vez en Roma en 1587. Describe las batallas habidas des-

\footnotetext{
${ }^{38}$ Cartas y avisos diferentes a don Juan de Zúñiga en 1581. Colección de libros españoles raros o curiosos (Madrid, 1887), p. 18.

39 Este tema está ampliamente desarrollado Carlos Alonso, «El P. Simón de Moraes, pionero de las misiones agustinianas en Persia», Analecta Agustiniana 24 (1979) 343-372.
} 
de 1576 hasta 1585, con mapas, nombres, etc. Imprimía la obra Francisco Sánchez, en Madrid en 1588. Era una fabulosa propaganda a favor de los persas que tenía su origen en la misma corte, por cuanto está dedicada al secretario real Juan de Idiáquez, uno de los hombres de confianza de Felipe II. Los resultados cristalizaron en nuevas misiones españolas a la lejana corte de Abbas I, muy memorables, que habían de producirse en el siguiente reinado. ${ }^{40}$ En este sentido, el año 1618 fue un punto de referencia, pues públicamente se alababa en Madrid la acción de Persia arrebatando cuantas tierras podía a los turcos y asentando embajadores permanentes en la corte española, con el doble fin principal de fomentar el comercio y propagar la fe cristiana, tal como prometía el Sha. ${ }^{41}$

40 Andrés DE FLORES, Relación muy verdadera: que trata de las brauas y cruelisimas batallas, y balerosos rencuentros, y las crueles muertes de tantos y tan soberuios Turcos tan balerosos y Capitanes y famosos Basanes que en las batallas a dado el baleroso Rey de Persia al soberuio y poderoso campo nunca visto, que el gran turco embio a la Persia..., (Burgos, por Santillana, 1586), 4 hoj., $4^{\circ}$, en la Biblioteca Nacional de Madrid, VE/193-8. Giovaani Tommaso Minadoi, trad. Antonio HerRERA Y TORDESILlas, Historia de la guerra entre turcos y persianos..., comenzando del año de 1576 que fueron los primeros motivos della, hasta el año de 1585 (Madrid, Francisco Sánchez, 1588) 1932 h, 4 . Biblioteca Nacional de Madrid, R/23810.

${ }^{41}$ Relación verdadera de la muerte del gran turco Acomates y de los bandos y discordias sobre la sucessión de aquel impero, juntamente con las razones y causa de su muerte. Dase quenta de la guerra que le da el rei de Persia y las tierras que le va ganando, y assimismo del buen fin que se espera mediante Dios para prouecho y seruicio suyo, Impressa con licencia, en Seuilla, por Francisco de Lyra, a la entrada de la calle de las Palmas, año de 1618. «Destas discordias y ciuiles guerras ha tomado ocasión el rey de Persia para restituirse y hazerse señor de todos los reynos que pertenecen a su corona cuyo dominio los turcos le auían vsurpado. Y no parando aquí el daño, antes asiendo la ocasión de los cabellos, pareciéndole no le ofrecería el tiempo otra en que tan a menos costa se pudiesse hazer, pagado de los agrauios que de la casa otomana auía recebido, se fue entrando y señoreando de muchas prouincias y ciudades pertenecientes al imperio turquesco, cuyos dos señores diuisos tienen tanto que hazer en defenderse vno del otro que no les queda lugar para acudir a reparar los daños que por otra parte le haze el persiano. El atendiendo a las cosas de la guerra y no descuidándose con las del gouierno, y queriendo segurar sus negocios para lo de adelante, tiene sus embaxadores en Madrid tratando entre otras cosas de passar vna grussa feria que se haze en Alepo, a la ciudad de Ormuz, donde tienen sus fuerças y presidios los portugueses. En lo qual pretende el persa dos cosas importantes a los reinos de España y dañosíssimas al imperio del turco. La primera y más principal es la de los intereses que se le pueden seguir al rey, nuestro señor, por ser el trato desta feria muy gruesso y adonde acuden la mayor parte de los mercaderes de toda la Turquía, Persia y muchos reynos y prouincias del Asia, más de trecientas leguas alrededor. La otra razón es que el persa queda obligado a sustentar aquella tierra con su gente, juntamente con los portugueses que confinan por aquellas partes de la India con aquellas prouincias, contra todo el poder de los turcos y moros, todo el mayor daño de la casa otomana, cuyo imperio según el parecer de muchos va ya tan en los fines que sin duda se acabará presto, sobre lo qual dize Antonio Torcato, autor graue, en vn pronóstico suyo, que no avrá más de catorze o quinze turcos, y el que murió aora es el decimoquinto, con cuya muerte se han dispuesto las cosas de manera que o sus sucessores lo acabarán con crueles guerras, o por lo menos lo dexarán de manera que fácilmente entre en poder de diferentes señores, pues nunca reynos tiranizados son permanentes, particularmente quando con ciuiles guerras sus propios señores le van enflaqueciendo las fuerças para que más fácilmente los que buscan esta ocasión la tengan de señorearse dellos sin resistencia. Permita Dios nuestro Señor, que a estos principios del bien de España y pérdida de Turquía les veamos los buenos fines que

Hispania Sacra, LXII

125, enero-junio 2010, 213-241, ISSN: 0018-215-X 
Respecto a Matías Bicudo, hay datos que confirman que a partir de 1584 mantendrá contactos con el embajador francés en Venecia. Se había vuelto un gran defensor de la independencia portuguesa frente a la Monarquía hispánica. ${ }^{42}$ En ese año se puso al servicio del prior de Crato, don Antonio de Portugal, pretendiente a la corona portuguesa y enemigo, por tanto, de Felipe II. Fue enviado por don Antonio de Portugal a Constantinopla, pasó por Ferrara, donde contactó con un espía judío al servicio de Francia llamado Saúl Cohen. ${ }^{43}$ Hizo escala en Venecia secretamente, pero una vez descubierto, enseguida Felipe II, a través de su embajador en Venecia, ordenó que se hicieran todas las diligencias necesarias para que fuera hecho prisionero. ${ }^{44} \mathrm{Hubo}$, por consiguiente, una serie de intentos infructuosos para sacarle de Venecia y proceder a su prisión. ${ }^{45}$

A pesar de estos desengaños, la Santa Sede buscó el modo de enviar algún embajador a Persia. En 1584 Gregorio XIII encomendó, por inspiración del cardenal Fernando de Médicis, al caballero florentino Giovan Battista Vecchietti una importante misión en Persia. Debía convencer al Sha para que perseverara en la guerra contra los turcos, prometiéndole ayuda militar procedente del papa y de Felipe II. El rey de España ya había enviado en misión similar al agustino padre Simón de Moiras. El pontífice emanaba por fin un breve acreditativo para el Sha con fecha del 28 de febrero de 1584. Una de sus misiones principales era conseguir manuscritos en lengua árabe, persa y turca. ${ }^{46}$ Llegó a Ormuz el 29 de

prometen para que assí nuestra santíssima fe se propague y estienda más libremente por todas aquellas partes para más honra y gloria de nuestro Señor».

42 Archivo General de Simancas. E. 1517, 1, 9, 23, 24, 30.

${ }^{43}$ Archivo General de Simancas. E. 1260, 94. Mathias Bicudo al embajador Francés en Venecia, Ferrara, 4 junio 1585. Archivo General de Simancas. E. 1260, 98 y 100 dos cartas de Bicudo para Saúl Cohen.

${ }^{44}$ Archivo General de Simancas. E. 1340, 26, 33, 37, 73. 1583-1584.

45 Archivo General de Simancas. E. 1341, 83. «Juan Bautista de Tassis me escribió a los 20 y 21 de febrero como don Antonio enviaba a Constantinopla a un fraile que se llama Matías Bicudo, que antes que tomase el hábito de San Francisco sirvió a V. M. por orden de don Juan de Austria, que está en el cielo, en Ragusa, y otras partes el año 73 y $74 \ldots$ y le detuviese como fraile apóstata». Cristóbal de Salazar a Felipe II, Venecia, 2 mayo 1583. AGS. E. 1341, 4. En lo de tomar a Matías Bicudo no se pudo efectuar por haber mudado de parecer el embajador de Francia y también porque le socorrieron agora para pasar en Constantinopla con 700 ducados, como Saúl Cohen me ha dicho, dejándose ir a Ferrara por esto, y aunque con el nuncio he hecho toda diligencia posible para que se prendiera, por ser nuevo y haber sido dos fiestas juntas ayer y anteier no se ha podido hacer diligencia en el oficio de la inquisición para prenderle, y ha sido necesario a los 24 de éste dar información de cómo andó sin hábito y que está fuera de la religión, porque a otra manera no se diera licencia para prenderle, porque es menester el brazo seglar y siempre se hace así, y ha sido gran impedimento, porque la inquisición no tiene ministros para prender, no obstante que se ha visto por una carta que el papa ha mandado se prenda. Y hanme avisado que partió anteier el Matías sin saberse por qué parte salió de aquí, ni aun de los mismo de la casa del embajador, porque salió sin ser visto, sino de uno que le abrió la puerta antes del amanecer, Cristóbal de Salazar a Felipe II, Venecia, 27 julio 1585.

${ }^{46}$ La relación del viaje está publicada en Ugo TuCCI, «Una relazione di G. B. Vecchietti sulla Persia e sul regno di Hormuz 1587», Oriente Moderno (1955) 149-160. 
junio de 1587, realizó su misión escrupulosamente y regresó a Italia, pasando por Madrid en 1589 para informar al rey. Sabemos que el Sha le entregó una preciosa carta en persa para el papa -escrita con letras de oro, salvo la firma del Sha, por humildad- en la que le decía que necesitaba dos expertos artilleros, dos fundidores, dos arquitectos para construir fortalezas, dos técnicos que supieran asaltar fortalezas y dos sargentos mayores que conocieran bien el arte de escuadronar, lo cual implicaba que supieran matemáticas, concretamente hacer raíces cuadradas. Estas demandas eran fundamentales, consciente el Sha de la inferioridad militar de su ejército frente al otomano. Poco tiempo después llegaron los hermanos Sherley, uno de los cuales, Antonio, parece que colaboró en la organización del ejército persa. ${ }^{47}$

Vecchietti portó consigo un buen número de libros árabes, entre los cuales estaba una Biblia en árabe, que dejó en Egipto al año siguiente, en nueva misión pontificia. Gregorio XIII se interesó por esos libros y ordenó al padre jesuita de ascendencia judía Giovanni Battista Eliano, legado apostólico en Egipto, como queda dicho, que los comprara, los cuales costaron 300 escudos. ${ }^{48}$ Vecchietti volvió a Persia en 1601, se quedó luego en Ormuz y fue consejero político del virrey portugués Diego Núñez hasta 1603, después pasó a la India. En Jaipur cayó enfermo, pero fue hospedado y protegido por el padre jesuita Francesco Corsi, florentino como él, que conocía perfectamente el idioma persa. Este jesuita había nacido en 1568, ingresó en la Orden en 1587, fue enviado a Goa en 1599, luego destinado en misión diplomática ante el Gran Mogol, murió en 1633, dejando 36 años de servicios apostólicos en la India. Fue maestro de los sobrinos del emperador Jahngir en Uttar Pradesh y capellán del príncipe armenio Mirzâ Zu'lkarnai, militar al servicio del Gran Mogol. ${ }^{49}$ Giovan Battista Vecchietti pudo regresar a Roma, tras arriesgadas aventuras, en octubre de 1608, allí trabajó en la Biblioteca Oriental, murió el 8 de diciembre de 1619. También debemos mencionar la actuación del padre Jerónimo Javier, traductor de los Evangelios..$^{50}$

\footnotetext{
${ }^{47}$ Sobre la carta del Sha, véase E. Rossi, «Elenco dei manoscritti persiani della Biblioteca Vaticana», Studi e Testi 136, (Città del Vaticano, 1948). Se mencionan dos cartas de Abbas a Clemente VIII (ASV. Vat. Pers. 164 y 165).

48 Roberto Amalgià, «Giovan Battista e Gerolamo Vecchietti, viaggiatori in Oriente», Atti della Accademia Nazionale dei Lincei 9 (1956) 313-350, 319. A. VACCARI, «Una bibbia araba per il primo Gesuita venuto al Líbano», Mélanges Université Saint Joseph 10 (1925) 79-104.

${ }^{49}$ E. HAmBYE, «Francesco Corsi», en DHCJ, I, p. 969.

50 «Evangelhos em Persa». Nota de la Biblioteca de Ayuda: [São Mateus, São Lucas, São João e São Marcos]. É cópia, completa, de um protótipo executado em 1328 (728) da Hégira, pelo [arménio?] Sarkis Loge ibn Amir-i Malek [grafia latinizada] e provavelmente pertencentes à série de cópias mandadas executar pelos jesuítas Jerónimo Xavier e Manuel Pinheiro, na corte do Grão Mogol, no início do século. [notícia redigida por A. Sidarus]. O exemplar da Ajuda, na fl. 166 traz grafada a indicação do colofão como «Dhul-Qiida ano 728 Hégira intérprete Loc Sarkis [de sua] escrita e punho.» Códice ms., 160x240 mm., de
} 
Nos interesa resaltar que entre las instrucciones que había recibido del cardenal de Florencia estaba comprar en Persia libros en árabe, gramáticas del árabe en persa y turco y al revés, y conseguir algún libro en persa y árabe con bellos caracteres. Apasionado con la búsqueda de la Biblia en persa, le escribió al papa en 1606 desde Ispahán que tenía esperanza de encontrar en alguna ciudad de Persia donde antes hubo cristianos todos los libros del Nuevo Testamento, si bien ya había logrado hacerse con los Evangelios en persa. Lo cierto es que Paulo V, Camillo Borghese, conoció a Vecchietti en Madrid, cuando fue nuncio extraordinario en esa corte en 1593, y ambos trataron durante varios meses bajo el mismo techo la importancia de Persia en el concierto internacional. Sus sueños se hicieron realidad, Vecchietti había aprendido correctamente el persa y estaba traduciendo el libro de Ester porque esta reina era persa. ${ }^{51}$ Además, contamos con una misiva del Sha para el papa y una respuesta de éste para aquél en septiembre de 1609.52

\section{El Pontificado De Sixto V (1585-1590)}

Los turcos estarán en guerra contra los persas en desde 1578 a 1590, obteniendo el imperio otomano el dominio de Georgia, Erivan y la mayor parte de Armenia. El apogeo de Murat III (1574-1595) coincidía con el ocaso de Muhammad Khudabanda (1578-1588). ${ }^{53}$ Esta crisis tendrá también consecuencias para la Monarquía hispánica. En 1582 Felipe II había pidió al virrey de la India que reiterara los ofrecimientos anteriores al Sha Tahmasp, pero éste había muerto en 1576 y le sucedió Haidar Mirza, que fue asesinado ese año, y luego reinó Khudabanda. Esto demuestra el gran desconocimiento que había en España de los acontecimientos que se vivían en Persia, lo único importante era que no dejaran de hacer la guerra a los turcos. El virrey de Nápoles despachaba

$217 \mathrm{fl}$., em papel não ocidental, iluminado, em caracteres pérsicos a negro e vermelho (títulos), sob enquadramento linear (azul, vermelho e ouro) em todas as folhas. Na fl. 1v., iluminura em fl. inteira, com cruz de braços trilobados, decorada, com pedestal, sobre fundo de folhas a ouro e enquadramento com decoração fitomórfica, de fundo a têmpera azul sob ramagens a ouro e flores a vermelho, branco e ouro, idêntico ao da cruz. Na fl. 2, iluminura igual à da fl. anterior, mas com o monograma IHS, a ouro, da [Companhia de Jesus ?], que sobrepõe um pequeno coração, a vermelho, com dois pregos (cravos) em aspa. Encadernação em carneira, com estojo, ferros a ouro. Cod. Ilum. 52-XIII-32.

${ }^{51}$ Biblioteca Apostolica Vaticana, Cod. Barb. Lat. 4602, 190. G. B. Vecchietti a Paulo V, Ispahán, 15 julio 1606, en Roberto AMALGià, «Giovan Battista e Gerolamo Vecchietti, viaggiatori in Oriente», Atti della Accademia Nazionale dei Lincei 9 (1956) 313-350, 348-350.

52 Biblioteca de Ajuda. Cod. 46-X-22 Carta do xá da Pérsia, Abbas, ao Papa Paulo V, e Breve do Papa, em resposta, datado de 9 de Setembro de 1609. (Rerum Lusitanicarum, vol. XLVI; Symmicta Lusitanica, tomo 39 , fls. 202-207v.).

${ }^{53}$ Rhoads MyURPHEY, Ottoman warfare, 1500-1700 (London, 1999), p. 4. Abbas I recuperará Tabriz en 1603 y Erivan en 1604. 
por orden real al armenio Juan Bautista a la corte del Sha para firmar una alianza. El rey de Persia aceptó la propuesta de Felipe II y despachó de nuevo a Juan Bautista con una carta personal y un emisario suyo. Llegaron a la India, donde el nuevo virrey don Francisco de Mascareñas tenía orden de entablar negociaciones con el Sha, por lo que el virrey pidió al agustino fray Simón de la Concepción de Moraes, que hablaba el persa, que fuera a la corte de Sha para concertar definitivamente una alianza. Fray Simón pidió a Gregorio XIII que uniera a los príncipes cristianos para luchar contra los turcos, a la vez que le daba cuenta de su misión en Persia. El Sha Tahmasp le nombró preceptor de su hijo, porque era un experto matemático. El Sha decidió enviarlo junto con un embajador persa a la corte de Felipe II, pero la nave que los traía a Europa naufragó en 1585, si bien es posible, según otra versión -la de fray Félix de Jesús-, que fray Simón fuera envenenado por el armenio que les acompañaba. ${ }^{54}$

En el corazón del imperio turco se tenía especial temor a los persas y, concretamente, estaban preocupados por los numerosos gastos que allí se hacían. Se podía decir con razón que Persia era para el Imperio otomano el Flandes de Felipe II, o Candía para el dux de Venecia, o Irlanda para Isabel I, precisamente porque los gastos por defender y ocupar esos territorios eran grandísimos y la renta era de poca consideración. Además, los turcos ya no volverían a recibir ayuda de los tártaros, porque éstos habían perdido toda esperanza, toda vez que los turcos estaban a punto de comenzar una guerra contra los moscovitas, a cambio de la ayuda de los tártaros para luchar contra los persas, según se desprendía de una carta dirigida al papa Sixto $\mathrm{V}$ de un espía pontificio infiltrado en los ejércitos turcos que luchaban en Persia. Los turcos, desprovistos de caballería por «la lunga e faticosa guerra di Persia», temían la fuerza militar de los georgianos y moscovitas, de modo que si se unían todos sus enemigos podían perder Siria y Egipto. Para colmo, habían perdido la alianza de los tártaros porque eran incapaces de atacar Moscú. Por esta razón buscaban la paz con los persas. Pero a quien más temía Murat II no era al Sha, sino a Felipe II, por su capacidad de sobornar a los mandos militares otomanos. ${ }^{55}$ Poco después, en 1601, el embajador persa Antonio Sherley propondrá a Clemente VIII un ataque a Siria o Palestina tanto por la facilidad del objetivo como por abrir un frente bélico donde las tropas del Sha llegaran a tiempo. ${ }^{56}$

54 Carlos Alonso, «Nueva documentación sobre las misiones agustinianas en la India y Persia (1571-1609)», Analecta Agustiniana 33 (1970) 309-393. Arnulf Hartmann, OSA, «The Agustians in Golden Goa. A manuscript by Felix of Jesus OSA», Analecta Agustiniana 30 (1967) 13

55 Archivio Segreto Vaticano. Varia Politicorum, 159, 61-82. Relatione di personaggio qualificato sopra lo stato del turco. «Havendo S. M. tanto oro dall'Indie non gli corrompa i ministri per intendere i suoi secreti et anco per divertire le guerre da suoi paesi caricandoli altri, et di più per causargli alcuna sollevatione ne suoi stati et fino nei propri figlioli...», 68v.

56 Archivio Segreto Vaticano. Borghese IV, Vol, 52, 334-337, en Carlos Alonso, «Embajadores de Persia en las Cortes de Praga, Roma y Valladolid (1600-1601)», Anthologica Annиa 36 (1989) 212. 
El clima de entendimiento hispano-persa facilitó el asentamiento de los agustinos en Persia, sobre todo desde el advenimiento al trono de Abbas I en 1587, que estableció la capital en Ispahán. Se trataba de aprovechar desde Europa la enconada rivalidad entre persas y turcos, como ya anteriormente se había intentado. El nuevo Sha Abbas hubo de firmar la paz con los otomanos en 1590 , con gran pérdida de territorio (reinos y principados georgianos). Los armenios decidieron entonces pedir ayuda a la Santa Sede y al rey de España. Querían recibir refuerzos militares y estaban dispuestos a aceptar el vasallaje del papa y del rey de España y a recibir misioneros que llevaran la fe católica. Aseguraban la colaboración para recuperar los Santos Lugares y Constantinopla. Esto no era nuevo, situación similar la encontramos en Grecia, Túnez, e incluso Irlanda. Todos dispuestos a ser buenos católicos vasallos del rey de España. Una cosa eran las palabras y otra muy distinta los hechos. ${ }^{57}$

\section{El Pontificado de Clemente VIII (1592-1605)}

Pese a los fracasos, Felipe II perseveró en su propósito de acordar la alianza persa. En 1594 ordenó a Matías de Alburquerque, virrey de la India, que enviase una embajada al Sha Abbas I, accediendo así al deseo manifestado por éste de mantener correspondencia diplomática. Dos años más tarde hace lo mismo con el nuevo virrey, don Francisco de Gama, pero esta vez insiste en que el enviado debía ser un noble, alguien que tuviera las mismas cualidades que Abreu cuando fue enviado por don Sebastián en 1571. El nuevo papa estaba atento a estos movimientos y sabía que lo importante era contar con el apoyo de los religiosos que se habían ido adentrando en esos lugares, agustinos, carmelitas y franciscanos. Clemente VIII quería asentar definitivamente la misión católica en Persia y pensó que quizá la Compañía de Jesús podía ser muy a propósito.

El factor que determinó el establecimiento de misiones católicas en Persia fue la llegada de dos frailes portugueses a Ispahán, el franciscano Alonso Cordero y el agustino Nicolás de Melo, así como la presencia del ex jesuita Francisco da Costa, dimitido de la Orden en $1598 . .^{58}$ Por esas fechas ya algún embajador persa enviado a la India había entrado en contacto con Orden, interesándose por sus actividades e incluso por cuestiones de fe. 59

\footnotetext{
57 Carlos Alonso, «Nueva documentación inédita sobre las misiones agustinianas en la India en Persia», Analecta Agustiniana 33 (1970) 309-393.

${ }^{58}$ Francisco DA CosTA (1563-post 1623), de origen indio, fue expulsado de la Orden en 1598, estuvo en Persia en 1599, llegó a Roma en 1600, el papa le encomendó una misión en Persia bajo patrocinio del rey de España. Véase la voz homónima firmada por F. B. MEdinA en DHCJ, I, 975-976.

${ }^{59}$ Doc. Ind., XVI, pp. 715-716. Carta annua de la provincia de India. «Vinieron este año a esta ciudad muchos embajadores, uno de los cuales era del rey de Persia, otro del Gran Mogol y dos del rey de
} 
En 1599 Nicolás de Melo envió a Europa al intérprete Angelo Armenio, que había trabajado para el duque de Mantua, con el fin de avisar al papa, a Felipe III, y al virrey de India, que el Sha enviaría una embajada a los príncipes cristianos para firmar una alianza defensiva, por cuanto en 1598 había vencido a los rebeldes usbek en la provincia de Corasán, de modo que Casbín dejó de ser la capital y se trasladó a Ispahán.

Estos religiosos se encontraron allí con los hermanos Sherley, implicados en la política exterior y defensiva del Sha. En efecto, Abbas I decidió enviar en 1599 una embajada encabezada por Huseim Ali Beg y Antonio Sherley al papa y a los príncipes católicos -emperador, papa, rey de España- para conseguir una coalición. Junto a ellos estaba el agustino padre Nicolás de Melo. El viaje duró más de dos años, atravesaron Rusia para llegar a Europa, por el camino se descubrieron intereses ocultos de Antonio Sherley, que se enfrentó a todos sus compañeros de viaje. Las negociaciones relacionadas con la liga antiturca tuvieron lugar en Praga, Roma y Valladolid. En Roma el papa decidió separar a los embajadores, Sherley regresaría a Persia -se quedaría finalmente en Venecia-, mientras que Huseim iría a España y desde Lisboa regresaría a Persia. ${ }^{60}$ En Valladolid Huseim fue muy bien tratado, asistió al bautismo de la infanta española, recibió 2.000 escudos, una cadena que valía 600, y cuatro más de 200 escudos para sus acompañantes más distinguidos, y otros 8.000 escudos para su viaje de regreso, y según un testigo, se fue «muy contento». ${ }^{61} \mathrm{Con} \mathrm{Hu}-$ sein llegaron a Valladolid en 1601 Uruch Beg (Juan de Persia), Ali Guli Beg (Diego de Persia) y Buyad Beg (Felipe de Persia). El mejor conocido es Juan de Persia por ser autor de las famosas Relaciones, el cual tuvo trato especialmente con el padre Francisco de Salazar, rector del colegio de Valladolid, y con el agustino Alonso Remón, capellán del limosnero mayor del rey, y corrector de su obra Relaciones, los cuales fueron los que le formaron en el cristianismo, según reconoce el propio Juan de Persia.

Casi al mismo tiempo que el Sha enviaba sus emisarios, Francisco da Costa y el capitán don Diego de Miranda, que habían estado en Persia por esas fechas,

\footnotetext{
Peguu. Y queriendo ver todos este colegio hablaron con el virrey el cual pidió al padre rector que quisiese condescender a tan buenos deseos mostrándoles particularmente las cosas que al propósito hicieron, de que quedaron con gran contentamiento del culto divino y religión cristiana».

${ }^{60}$ Sobre Nicolás de Melo (1578-1615) véase Gregorio DE SANTIaGo Vela, Ensayo de una biblioteca ibero-americana de la Orden de San Agustín, (Madrid, 1920), V, pp. 373-377; y Carlos Alonso, «El P. Nicolás de Melo, OSA. Embajador y Mártir», Misionalia Hispanica 15 (1958) 219-244. Sobre Antonio de Gouvea (1575-), Gregorio DE SANTIAGo Vela, Ensayo de una biblioteca ibero-americana de la Orden de San Agustín, (Madrid, 1920), III, pp. 253-279; Luis GIL - J. M. FloRISTÁN, «Las misiones luso-españolas en Persia y la Cristiandad armenia (1600-1614)», Sefarad 46 (1986) 207-219; J. M. Floristán, «Carta del Patriarca armenio David IV a Felipe III», Safarad 46 (1986) 197-205.

${ }^{61}$ Luis CABReRA DE CóRdoba, Relaciones de las cosas sucedidas en la corte de España desde 1599 hasta 1614 (Junta de Castilla y León, 1997), p. 122.
} 
fueron a Roma para narrar al papa las buenas intenciones del Sha respecto al cristianismo. Lo cierto es que el papa eligió en 1600 a Francisco da Costa y al capitán Diego de Miranda para que fueran a Persia como embajadores, lo cual provocó desacuerdo en Vecchietti, que acusaba a Da Costa de haber abandonado la Compañía de Jesús, «prete vagante» en Lisboa, y a Miranda de ser un indio, nacido en Ormuz, que se había desposado públicamente en Roma con una prostituta. No obstante las críticas, el cardenal de Como decidió enviar a tres emisarios a Persia, al español Luis Félix y a los portugueses Francisco da Costa y Diego de Miranda.62

Respecto a la legación persa y por hacer hincapié en la contribución de la Compañía de Jesús, hemos de señalar que a su llegada a Praga, Antonio Sherley, anglicano, pidió al nuncio que le proporcionara un confesor, porque quería volver al catolicismo. El nuncio le puso en contacto con el jesuita español Pedro de Bui$\mathrm{za}$, hombre «di molto valore»-a juicio del nuncio- $\mathrm{y}$ «bien conocido en la corte» -según dijo el embajador en Praga al rey-. Era un teólogo con grandes dotes diplomáticas. Sherley no quería que fuera un jesuita inglés o francés, sino español. Parece que hubo entendimiento entre los dos y trabaron amistad. ${ }^{63}$ En Roma también tuvo amistad con algunos jesuitas ingleses, consejeros de Felipe III, con Robert Persons (1546-1610) y es especialmente Joseph Creswell (1556-1623). El embajador en Roma -duque de Sessa- informó al rey por medio de una carta cifrada que Sherley y Persons eran buenos amigos. Sherley no se cansaba de decir en un sitio y en otro que el Sha estaba dispuesto a colaborar con 60.000 infantes y otros tantos jinetes en la lucha contra el turco. Pedía a cambio colaboración concreta, intercambio de embajadores, libertad de comercio, apoyo militar, en especial que las barras de hierro que llegaban a Ormuz fueran más largas para poder fabricar las espadas según las medidas acostumbradas por los persas.

Abbas I, hijo y esposo de cristiana, parecía mostrar inclinación al cristianismo, según había dicho Da Costa al papa. Su mujer era hija de Simón Causeno -del linaje de los reyes de Georgia-, y Allaverdi Khan era amigo de los cristianos. El ex jesuita redactó un largo informe sobre Persia que entregó al embajador en Roma, el duque de Sessa, el cual a su vez lo envió a Felipe III. ${ }^{64}$ Por otro

62 Roberto Amalgì̀, «Giovan Battista e Gerolamo Vecchietti, viaggiatori in Oriente», Atti della Accademia Nazionale dei Lincei 9 (1956) 313-350, 324.

${ }^{63}$ Archivio Segreto Vaticano. Borghese III, 87, 133. Nuncio de Praga, Spinelli, al cardenal de San Jorge, Praga, 13 noviembre 1600. AGS. E. 707, 23-24. Guillén de San Clemente a Felipe III, Praga, 10 marzo 1601. Vid. Carlos Alonso, «Embajadores de Persia en las Cortes de Praga, Roma y Valladolid (1600-1601)», Anthologica Annua 36 (1989). Pedro de Buiza, (Medina de Rioseco 1561-†Toledo 1626), teólogo, hizo su profesión en Roma en 1600, fue confesor del conde de Fuentes, gobernador de Milán, murió como prepósito de la casa profesa de Toledo.

${ }^{64}$ No hemos encontrado en el Archivo General de Simancas el informe remitido por Acosta a Felipe III. Sin embargo, existe un largo informe remitido al papa, que posiblemente serían muy parecidos. 
lado, mantuvo largas conversaciones con algunos jesuitas españoles en Roma, con Bartolomé Pérez y Juan Álvarez, asistentes español y portugués respectivamente del padre general Acquaviva, así como con el padre Sebastián Rodríguez. Los órganos directivos de la Compañía de Jesús tuvieron dudas sobre las verdaderas intenciones de Francisco da Costa, porque se inclinaba con demasiado fervor hacia el plan militar del Sha. Aunque Francisco da Costa dejó la Compañía en 1598, fue readmitido de nuevo cuando fue enviado como legado a Persia, toda vez que tenía el cometido de hacer llegar a Persia, vía Ormuz, a un buen número de jesuitas procedentes de India. ${ }^{65}$

El papa Clemente VIII en 1601 se ilusionó por las posibilidades de la embajada y envió en misión diplomática a Da Costa en calidad de legado a latare ante Abbas. Acquaviva debía, por su parte, conseguir ayuda de Felipe III para que facilitara el paso de jesuitas a Persia. Se debe tener presente que en 1600 Felipe III ya había enviado tres agustinos a Persia para solicitar al Sha que prosiguiera la guerra contra los turcos, por eso el favor real a los jesuitas provocó entre los agustinos cierto recelo. Fue tal la antipatía de los agustinos a esta misión jesuítica, que el arzobispo de Braga, que era el agustino Agustín de Castro, conminó al rey a que desistiera de favorecer la misión de los jesuitas en Persia. Los agustinos creían tener la exclusiva de esas tierras, porque ellos habían comenzado su misión en Ormuz en 1571, cuando los jesuitas habían abandonado el lugar por lo insalubre del lugar. En 1572 ya había en Orzmuz y Goa doce agustinos, de hecho establecieron casas en Bandar Abbas, en Mascate y otros lugares. Los embajadores remitidos por Felipe II habían sido agustinos, como el padre Simón de Moraes. El progreso de la Orden allí había sido enorme, de modo que en 1600 ya contaban con más de 200 miembros. Permitir que fueran jesuitas en vez de agustinos podía ser tomado como un insulto. ${ }^{66}$ En definitiva, debido a las presiones de los agustinos finalmente el rey no autorizó el proyecto de enviar jesuitas. No obstante, Da Costa fue a Persia con el soldado Diego de Miranda, pero por discordias entre ambos, de dividieron. Sólo llegó a Ispahán Da Costa, que fue presentado como legado apostólico por los agustinos que residían allí. El legado fue más un consejero militar del Sha que un diplomático, de hecho participó en las campañas militares contra los turcos. Este dato, que

\footnotetext{
ASV. Borghese, II, 20, 158-159, «Informatione di Francesco da Costa, sacerdote portuguese, venuto dall'India, alla Santità di Nostro Signore intorno all'ambasciata del Persiano», publicado por Carlos Alonso, «Una embajada de Clemente VIII a Persia (1600-1609)», Archivum Historiae Pontificiae 34 (1996) 7-125, 77-79.

${ }^{65}$ Archivo General de Simancas. K. 1630. Relación de la embajada que el rey de Persia envió con don Antonio Sherley y Cusán Alibey, persiano. Roma, 8 junio 1601, publicada por Carlos ALonso, «Embajadores de Persia en las Cortes de Praga, Roma y Valladolid (1600-1601)», Anthologica Аnпиа 36 (1989) 223-226.

${ }^{66}$ Carlos AlONSo, «El P. Simón de Moraes, pionero de las misiones agustinianas en Persia», Analecta Agustiniana 42 (1979) 343-372.
}

Hispania Sacra, LXII

125, enero-junio 2010, 213-241, ISSN: 0018-215-X 
revela el mismo Sha en carta al papa, resulta revelador de las cualidades militares de Francisco de Casto. Es probable que tuviera relación con el general persa Allahverdi Khan, que era considerado un amigo de cristianos. ${ }^{67}$

Los preparativos de la legación de Francisco da Costa se hicieron con prisa, pero no se olvidaron de señalar que lo más importante era establecer una misión permanente de jesuitas en Ormuz, pese a las presiones de los agustinos. Pero ni los jesuitas ni los agustinos fueros los únicos en informar al papa de la situación en Persia, se tenían noticias por diversos conductos. Desde 1582 trabajaba en la Biblioteca Vaticana un armenio, llamado Tomás, que conocía perfectamente la lengua persa. Cuando llegó la embajada de Huseim Ali Beg fue, de hecho, el intérprete. Es más, el papa quiso que Tomás fuera con el embajador persa en su misión a España y Portugal para que actuara como su intérprete, si bien el embajador hablaba el turco y en España había un traductor oficial de esa lengua. Sabemos que durante su estancia en España el traductor de los persas no fue Tomás sino Diego de Urrea. Uno de los objetivos de Huseim en Lisboa fue embarcar gran cantidad de armas, lo cual se lo permitió el rey. Cuatro de los acompañantes del embajador se convirtieron al catolicismo y se quedaron en España, a su capellán musulmán lo mataron en Mérida los propios persas.

El consejo de Estado de Felipe III determinó en marzo de 1602 que en respuesta a la embajada de Huseim Ali Beg fueran como embajadores un jesuita, elegido por Fernando Niño de Guevara, cardenal de Sevilla e Inquisidor General, una vez hablara con el provincial de la Orden en Castilla, y un noble portugués, don Luis Pereyra de la Cerda. Los enviados fueron Francisco Girón y Gonzalo del Río, aunque finalmente no llegaron a zarpar desde Lisboa. Sí sabemos que en 1603 Luis Pereyra partió para Persia, adonde llegó al año siguiente. ${ }^{68}$ El papa, dadas grandes tensiones entre agustinos y jesuitas, fue partidario de que viajaran a Persia también algunos capuchinos, con el fin de que la misión católica tuviera más probabilidades de éxito ${ }^{69}$ Los agustinos también se opusieron a la presencia de los carmelitas. Todo se estaba complicando, entraban en juego muchos intereses particulares de jesuitas, agustinos, capuchinos, carmelitas, ten-

\footnotetext{
${ }^{67}$ Véase su voz homónima en la Encyclopaedia Iranica. Acosta dispondría de buenos conocimientos militares, posiblemente matemáticas, que podrían interesar al Shah. Para poder escuadronar había que saber hacer raíces cuadradas.

${ }^{68}$ ARSI. Cast. 6, 406v. Aquaviva al procurador Francisco Valdivieso, en Valladolid, Roma, 22 enero 1602. «añado ésta la otra para decir a v.r. dos cosas, la una es que con ésta le envío una instrucción que se ha de dar a enviar a los padres que van con el embajador persiano, pero v.r. la muestre primero al Señor Duque de Lerma para que vea si le parece quitar o añadir algo, y como Su Excelencia [duque de Lerma] lo dijere así se haga». Archivo General de Simancas. E. 191. Felipe III a Cristóbal de Moura, virrey de Portugal, Valladolid, 6 marzo 1602.

${ }^{69}$ Archivo General de Simancas. K. 1631, 217. Duque de Sessa a Felipe III, Roma, 25 noviembre 1602.
} 
siones entre embajadores, entre españoles y portugueses. No se percataban de que estaban poniendo en riesgo la posible alianza persa. Es llamativo que aunque según nuestros datos no parecía que hubiera ningún jesuita en Persia a principios del siglo XVII, según una carta de un mercader veneciano residente en Ispahán el Sah había ordenado que fueran expulsados los jesuitas. ${ }^{70}$

Se debe tener presente, por otro lado, que en 1600 Felipe III ya había enviado tres agustinos a Persia para solicitar al Sah que mantuviera la guerra contra el turco. Pero la situación político-religiosa cambió en Persia cuando llegó una misión de carmelitas que había sido enviada por Clemente VIII en 1601. El papa canceló la misión de Francisco da Costa al saber que había actuado con poca fidelidad a sus instrucciones. Era tal la confusión que se puede decir que no había seguridad en ninguna misión. Pero también por parte persa sucedía algo parecido, sus distintas embajadas terminaron en fracaso por la división entre sus componentes, como la separación y distanciamiento entre Huseim Ali Beg y Antonio Sherley. ${ }^{71}$.

No obstante, el Sha, que poco a poco se percató de estas divisiones entre los religiosos españoles y portugueses, decidió enviar a Francisco da Costa, después de estar tres años en Persia, como embajador a Roma en 1605, adonde llegó en 1607 vía Moscú.72 Pero ya era demasiado tarde. En 1606 el emperador había firmado una tregua con el turco, y Felipe III no apoyará a los persas en los frentes abiertos, es decir, en el Mediterráneo y en el Golfo Pérsico. $\mathrm{Al}$ año siguiente las relaciones se deteriorarán en tal extremo que el Sha estuvo dispuesto a expulsar a los religiosos, perseguir a los vasallos cristianos y tomar Ormuz.

\footnotetext{
70 Archivo General de Simancas. E, 1349, 172. Ver Luis GiL Fernández, El Imperio Luso-Portugués y la Persia Safávida (Madrid, 2006), p. 173.

${ }^{71}$ La bibliografía sobre viajes y viajeros occidentales a Persia es muy abundante, sobre todo con la publicación de sus memoriales y relatos de viaje. Hasta la embajada de Don García de Silva y Figueroa, estas misiones siempre estuvieron encomendadas a religiosos españoles y, sobre todo, portugueses; A Chronicle of the Carmelites in Persia and the Papal Missions of the XVIIth and XVIIIth centuries (Londres, 1939); Carlos Alonso, Ángel María Cittadino, OP, arzobispo de Naxiwan (+1629). Una iniciativa de Propaganda Fide a favor de armenia (Roma, 1970); Pietro Della Valle, I viaggi di —-, (Roma, 1668); A. DE GouvEA, Relaçam em que se tratam as guerras e grandes victorias que alcançou o grande rey de Persia Xa Abbas do grao turco Mahometto \& seu filho Amethe..., (Lisboa, 1611); R. Gulbenkian, L'ambassade en Perse de Luis Pereira de Lacerda et des Perès Portugais de l'Ordre de Saint-Augustin, Belchior dos Anjos et Guilherme de Santo Agostinho, 1604-1605 (Lisboa, 1972); J. DE San Miguel, Crónica de la provincia franciscana de San Miguel, (Madrid, 1989), A. Da SiLva Rego, Documentação para a história das missoes da padroado português do Oriente (Lisboa, 1955-1958).

72 Carlos Alonso, «Una embajada de Clemente VIII a Persia (1600-1609)», Archivum Historiae Pontificiae 34 (1996) 7-125. Véase también el informe que emitió para el papa, en Biblioteca Ajuda, Cod. 46-IX-22. Informação do P. Francisco da Costa, ao Papa Clemente VIII, acerca da sua missão, como embaixador na Pérsia. (Symmicta Lusitanica, tomo 15, fl. 433-438).
}

Hispania Sacra, LXII

125, enero-junio 2010, 213-241, ISSN: 0018-215-X 
En 1614 las noticias que llegaban a España confirmaban que había persecución contra los cristianos armenios y sirios y que los carmelitas y agustinos habían salido de Persia. Al instalarse de nuevo en Ispahán, las tensiones entre carmelitas y agustinos continuaron. Hubo varios momentos culminantes que se proyectaron sobre España con algunas publicaciones, en 1611 y en $1624 .^{73} \mathrm{El}$ acontecimiento central fue cuando el Sha cumplió su amenaza y con ayuda inglesa y holandesa tomó en 1622 Ormuz. En agosto de ese año se hizo una subasta pública en Londres con los bienes tomados en Ormuz, lo que influyó en el clima de desconfianza que se estaba operando en Madrid por la posible boda del príncipe de Gales con la infanta española. ${ }^{74}$ La Junta de Persia, creada para evitar la pérdida de Ormuz, no pudo evitar el desastre, aunque sí consiguió que las fortalezas lusas siguieran defendiendo sus intereses en el Golfo Pérsico protegiendo el monopolio comercial portugués..$^{75}$ Por tanto, todavía continuaron los religiosos en esas fortalezas. Llama todavía más la atención que el papa Urbano VIII enviara un breve al Sha Abbas, fechado el 10 de octubre de 1623, cuyo portador era Francisco da Costa, de nuevo otra legado del papa. Su misión era conseguir que se restituyera a los portugueses la isla de Ormuz. ${ }^{76}$

Las claves de interpretación política de estos cambios obedecen a dos aspectos. En primer lugar, las tensiones entre agustinos y carmelitas y el elemento

73 Antonio DE GouveIA, Obispo de Cirene (O.S.A.), Relaçam em que se tratan as guerras e grandes victorias que alcaçon o grande rey da Persia ... por mandado ... del Rey D. Felippe segundo de Portugal fizerao alguns religiosos da Ordem dos Eremitas de S. Augustinho a Persia / composto pello padre F. Antonio de Gouuea religioso da mesma ordem..., (Impresso em Lisboa: por Pedro Crasbeeck: vendese na rua romana en casa de Simao de Carualho ..., 1611). [13], 226 [i.e. 213], [4] h.; 4, en Madrid, Real Academia de la Historia, 5/1708. Próspero DEL Espíritu SANTO, (O. C. D.), Breve suma de la Historia de los sucessos de la mission de Persia de los Carmelitas Descalços, desde el año de 1621 hasta el de 1624 / escrita por el Padre Fray Prospero del Espiritu Santo... de la misma orden [Carmelitas Descalzos], (Madrid, por la viuda de Alonso Martín, 1626). 10 [i.e. 6] h.; Fol. Madrid, Palacio Real III-6474(9). Relación cierta y verdadera de la feliz victoria y prósperos sucesos que en la India Oriental han conseguido los Portugueses, contra armadas muy poderosas de Olanda, y Persia este año de 1624, la fecha en la ciudad de Goa, cabeça de aquel Reyno a 27 de Março, del dicho año, (Impreso en Madrid, en casa de Bernardino de Guzmán, 1625). BNM, Mss./2355.

${ }^{74}$ Martín Fernández de FigueroA, Conquista de las Indias de Persia e Arabia que fizo la armada del rey don Manuel de Portugal e de las muchas tierras, diversas gentes, extrañas riquezas y grandes batallas que allá hubo: en sumario del bachiller Juan Agüero de Trasmiera; introducción, edición crítica y notas de Luis GIL FERNÁNDEZ (Valladolid, Secretariado de Publicaciones e Intercambio Editorial, Universidad, 1999). García DE Silva FigueroA, Epistolario diplomático; edición y estudios preliminares de Luis GIL, (Cáceres, Institución Cultural «El Brocense», 1989). Véase: Niels STEENSGOARD, The Asian Trade Revolution of the Seventeenth Century (Chicago, 1974). Biblioteca Real de Madrid, Ms. II/2590, 16, 32-33. Marqués de Hinojosa a Juan de Ziriza, Londres, 30-octubre-1623. Sobre que no se le ha respondido al particular de la hacienda que llegó allí robada a portugueses y de los despojos de Ormuz.

75 Archivo General de Simancas. Secretarías Provinciales, 1467 (1622-1624). Junta de Persia.

76 Carlos Alonso, «Una embajada de Clemente VIII a Persia (1600-1609)», Archivum Historiae Pontificiae 34 (1996) 7-125. 
distorsionador de Francisco da Costa; y luego, las disputas constantes y vistosas entre españoles y portugueses. En suma, que los agustinos se opusieron a los jesuitas y los carmelitas españoles se opusieron a los agustinos portugueses. Pese a todo, fue el Sha quien en 1608 reclamaba la ayuda de las potencias cristianas, de ahí que enviara varias embajadas. Los carmelitas llegaron en 1607, y en su apostolado con los cristianos armenios, Antonio de Gouvea fue quien más hizo para llegar a los unidad con los armenios. ${ }^{77}$

En cuanto a los principios de la primera Misión de los jesuitas en Persia, no cabe duda, como reconoció en 1659 el padre francés Alexandre de Rhodes, que fue muchos años antes cuando la Santa Sede encargó a la Compañía una Misión en Persia. En principio parece que se refiere a la actividad de Da Costa como legado, sin embargo Rhode especifica que el papa dispuso que desde Goa fueran algunos jesuitas a Ispahán, disposición pontificia que se llevó a efecto, pero por circunstancias adversas, se hubo de posponer la Misión. Posiblemente fue testigo de esta primera Misión en 1619, cuando llegó a Goa y allí permaneció por dos años y medio. En 1648 aparece en Ispahán procedente de Macao. Decidió misionar en esas zonas. ${ }^{78}$

\section{CONCLUSIONES}

Los soberanos Safawíes, los Habsburgo y los papas están realizando la misma política con respecto al enemigo común. A lo largo del siglo XVI los contactos entre persas y españoles se mantuvieron por vía del gran número de religiosos católicos que se acercaron a las tierras iraníes, como Gaspar de Berze, Francisco da Costa, Alonso Cordero, Nicolás de Melo, etc. En este proceso influye la propia política persa con respecto a las minorías cristianas y su lucha contra los turcos, así como la expansión territorial y comercial de las potencias europeas. Hay elementos difíciles de calibrar, donde entran en juego las inclinaciones personales, como las tendencias a la solución militar adoptadas por algunos religiosos. Hemos querido subrayar la importancia de algunos jesuitas respecto a Persia. Francisco de Borja fue partidario de la alianza militar, secundando la iniciativa de Pío V, si bien no siguió caminos más expeditivos.

77 Luis Gil - J. M. Floristán, «Las misiones luso-españolas en Persia y la cristiandad armenia (1600-1614)», Sefarad 46 (1986) 207-218. Relaciones de Pedro Teixeira d' el origen descendencia y succession de los Reyes de Persia, descendencia y succession de los Reyes de Persia, avtor dende [sic] la India Oriental hasta Italia por tierra (Amberes, en casa de Hieronymo Verdussen, 1610), [8], 384, [8], 116 [i.e. 216], 16 p.; $8^{\circ}$, en Madrid, Biblioteca Francisco de Zabálburu, 41-112.

78 Arnold T. WiLsON, «History of the misión of the Fathers of the Society of Jesús, established in Persia by the Reverend Father Alexander of Rodhes», Bulletin of the School of Oriental Studies, 3/4 (1925) 675-707. Véase voz homónima de J. LópEZ-GAY en DHCJ, IV, 3342-3344.

Hispania Sacra, LXII

125, enero-junio 2010, 213-241, ISSN: 0018-215-X 
Sin embargo, Matías Bicudo y Francisco da Costa tomaron posturas más extremas, fueron verdaderos colaboradores de los persas en su lucha contra los turcos. No se limitaron a meras actividades apostólicas, sino que optaron por posturas extremas, lo que implicó inmiscuirse en cuestiones militares, espionaje y planes de conquista, como los trazados por Matías Bicudo. Esta misma opinión la vemos en los jesuitas Persons y Creswell, que entablaron contacto con Antonio Sherley. En la siguiente centuria la contribución de la Compañía de Jesús seguirá otros derroteros, toda vez que ya no fueron ni españoles ni portugueses, sino franceses los que lograron instalarse allí, con hombres como François Rigordi, Aimé Chezaud, Alexandre de Rhodes. 